\title{
Rainfall Threshold Analysis and Bayesian Probability Method for Landslide Initiation Based on Landslides and Rainfall Events in the Past
}

\author{
Hien Minh Do ${ }^{1,2 *}$, Kun Long Yin ${ }^{1}$ \\ ${ }^{1}$ Faculty of Engineering, China University of Geosciences (Wuhan), Wuhan, China \\ ${ }^{2}$ Vietnam Institute of Geosciences and Mineral Resources, Hanoi, Vietnam \\ Email: *hien_dm@yahoo.com, yinkl@cug.edu.cn
}

How to cite this paper: Do, H.M. and Yin, K.L. (2018) Rainfall Threshold Analysis and Bayesian Probability Method for Landslide Initiation Based on Landslides and Rainfall Events in the Past. Open Journal of Geology, 8, 674-696.

https://doi.org/10.4236/ojg.2018.87040

Received: June 13, 2018

Accepted: July 20, 2018

Published: July 23, 2018

Copyright $\odot 2018$ by authors and Scientific Research Publishing Inc. This work is licensed under the Creative Commons Attribution International License (CC BY 4.0).

http://creativecommons.org/licenses/by/4.0/

(c) (i) Open Access

\begin{abstract}
In this paper a rainfall threshold and a Bayesian probability model are presented for the landslide occurrence of shallow landslides in Ha Giang city and the surroundings, Vietnam. The model requires the data on daily rainfall combined with the actual dates of landslide occurrences. Careful study on the database is a prerequisite for the paper. For this reason, selecting the input data was carried out carefully to ensure the reliable results of the study. The daily rainfall data covering a time span of 57 years was collected from a unique rain gauge station of National Centre for Hydro-meteorological Forecasting of Vietnam (from 1957 to 2013) and a landslide database with some landslides (37 of total of 245 landslides) that containing dates of occurrence, was prepared from historical records for the period 1989 to 2013. Rainfall thresholds were generated for the study area based on the relationship between daily and antecedent rainfall of the landslide events. The results shows that 3-day antecedent rainfall (with the rainfall threshold was established: $R_{T}=$ $40.8-0.201 \mathrm{R}_{3 \mathrm{ad}}$ ) gives the best fit for the existing landslides in the landslide database. The Bayesian probability model for one-dimensional case was established based on 26 landslides for the period 1989 to 2009, daily rainfall data with the same time and the values of probability varies from 0.03 to 0.44 . Next, the Bayesian probability model for two-dimensional case was generated based on 11 landslides, rainfall intensity and duration in three months (May, June and July) of 2013 and the values of probability ranges from 0.08 to 0.67 , and computed values of conditional landslide probability $P(A \mid B)$ from two-dimensional case of Bayesian approach are clearly controlled by rainfall intensity $>40 \mathrm{~mm}$ with rainfall duration $>0.3$ day.
\end{abstract}




\section{Keywords}

Rainfall Threshold, Antecedent Rainfall, Bayesian Probability, Ha Giang

\section{Introduction}

Landslide occurs every where on over the world, especially in the small and medium river basin, along traffic road, mountain foot area in the mountainous areas in the countries under the influence of climate and storms.

Landslide studies have been carried out from very long time ago until now. The main objectives of these researches are to understand, manage, monitor, control, prevent and mitigate the huge impacts of this natural phenomenon to human's life, socio-economic development, cultural infrastructure, environmental degradation...

To fulfill these objectives a lot of scientific articles related to this field were published. One of the most important landslide causative factors is rainfall data which are supposed as a triggering factor of landslide. The early studies about the rainfall intensities and duration associated with shallow landslides and debris flows were carried out by Caine [1]. He and some scientists who published their previous studies supposed that the effect of rainfall in producing shallow (less than 2 or 3 meters deep) landslide and debris flow activity is an obvious one, though one that is difficult to define precisely. This difficulty arises because rainfall only influences slope stability indirectly, through its effect on pore water conditions in the slope material and because its influence requires an interaction with other characteristics of the waste mantle.

Extreme rainfall conditions, when intensities remain high for long periods of time, must be accurately examined. In this case, any soil could become unstable. Hence, a better knowledge of the expected rainfall intensity and duration is fundamental for understanding the relationship with soil failure initiation and to establish different warning thresholds [2]. Prediction of landslide occurrence is not only a fundamental goal of hazard management but also a test of how well the process is understood. Forewarning of landslides may be provided in different ways. By far the most common approach is the recognition of landslide susceptibility from a spatial perspective [3].

Since the studies of Caine [1], information on the rainfall intensity-duration (ID) conditions that have resulted in slope failures was collected at various sites or regions worldwide, and different rainfall ID thresholds were proposed at the local, regional, and global scales (for reviews of the published thresholds and of the rationale for establishing and using rainfall thresholds see, e.g. [4] [5] [6] [7]). Rainfall-induced landslides often cause considerable damage to society. To analyze the primary causes of landslides, it is necessary to understand the relation between rainfall and the initiation of landslides [6] [7] [8]. Therefore, many studies have developed rainfall thresholds for landslide initiation using an empirical model or a physical (process-based) model [1] [3] [4] [6] [7] [8] [9]. The 
empirical thresholds refer to statistical analysis of the relation between rainfall and landslide occurrence [1] [6] [7].

Empirical methods for temporal probability assessment are based on the estimation of rainfall thresholds obtained by studying rainfall conditions that have resulted in landslides. They are usually contained in envelope curves based on variables such as cumulative rainfall, antecedent rainfall, rainfall intensity, and rainfall duration [1] [2] [3] [4] [5] [9]-[19]. The most commonly used empirical model is based on the rainfall intensity and duration. This threshold model requires data with high quality and temporal resolution (at least hourly rainfall data), which are not frequently available. Other models based on antecedent rainfall work with daily rainfall data, which are relatively simple and inexpensive to measure over large areas [11].

Recent studies introduced improvements using statistical methods for a more precise constrain of the ID threshold. This is the case of Bayesian inference method (e.g. [6] [20] [21] and the quantile regression [8]). Moreover, few attempts have been carried out to estimate temporal probability of slope failure [11] [22].

In this paper, we propose a rainfall threshold for landslide initiation was estimated based on the relationship between the rainfall events and the historical landslide records. Then, the rainfall threshold was validated using the landslide events in 2000, 2007, 2008 and 2013. The method requires complete information on landslides including the dates of occurrence in order to correlate them with rainfall. Besides this method, Bayesian approach will be apply to estimate the probability of landsliding conditional to characteristics of rainfall events. The applications of these methods are based on the quality of landslide information (timing and location). So we used a data set consisting of 37 events that occurred between 1989 and 2013 from a database of 245 landslides occurred in the study area. Daily rainfall data were provided by a unique rain gauge station in the study area and collected rainfall data from 1957 to 2013.

This method is applied to assess landslide currently induced by rainfall in the $\mathrm{Ha}$ Giang city and the surroundings, one of the most high risk potential of landslide hazard in mountainous area of Vietnam as well as showing the level of the probability of landslide occurrence in the region. This study area was selected because of the availability of historical landslide records including the dates of occurrence of the landslides, and daily rainfall records from a rain gauge station.

\section{Study Area}

Ha Giang city and the surroundings are located in Ha Giang, one of the northern mountainous provinces in Vietnam (Figure 1). It covers an area of about $779 \mathrm{~km}^{2}$ between longitudes $104^{\circ} 52^{\prime} \mathrm{E}$ and $105^{\circ} 18^{\prime} \mathrm{E}$ and latitudes $22^{\circ} 34^{\prime} \mathrm{N}$ and $22^{\circ} 56^{\prime} \mathrm{N}$. The elevation in the region ranges from 68 to $2000 \mathrm{~m}$ above sea level and the mountainous region is strongly dissected and steep. It includes high mountains in the north, south and west but the distribution is not equability and the altitude is gradually decreases to the middle of the region. Moreover, the 


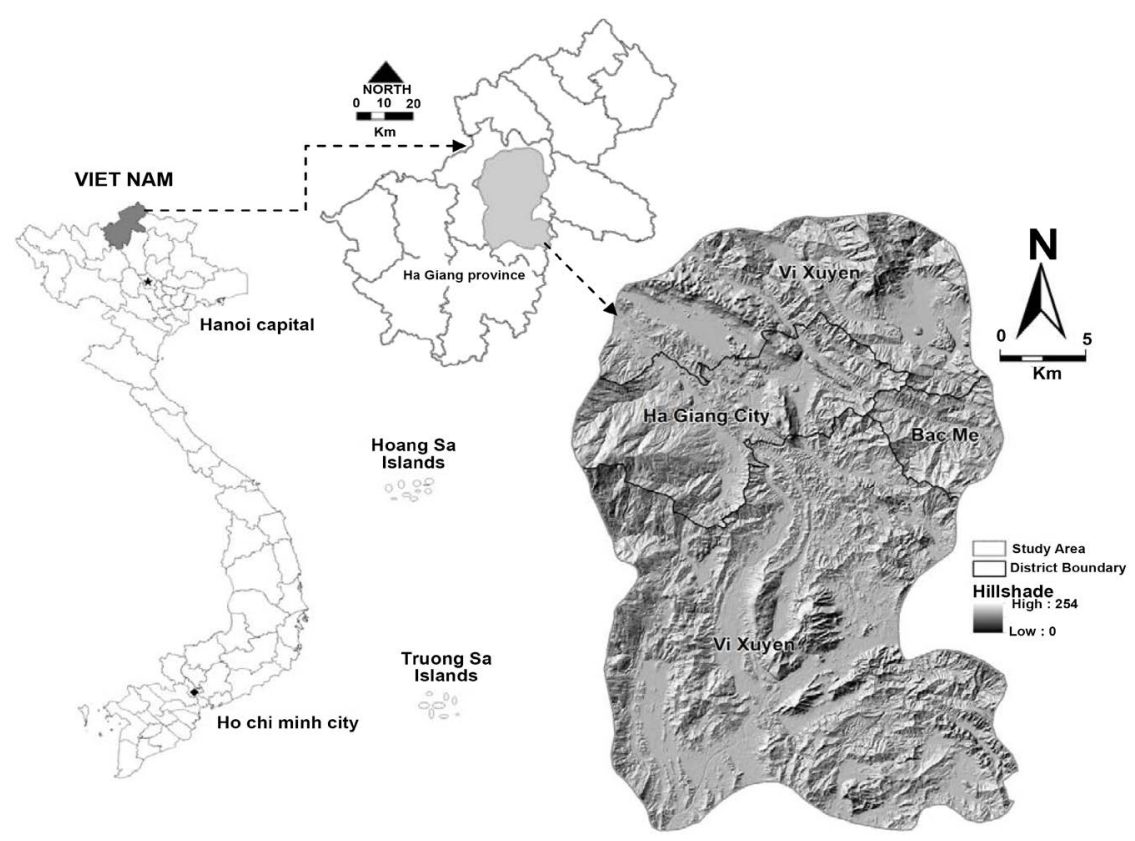

Figure 1. Location map of the study area.

karstic area is also representative of the north part of study area. Beside the drawback of terrain, here is also a tectonically active area with the complex of fracture zones, faults system and other important feature is dense drainage network with river and streams that landslides occur frequently as one of the most common natural disasters.

Geologically, the area comprises of limestone, sandstone, silty sandstone, black clay shale, quartz-biotite schist, sericite-chlorit schist, mica schist, green schist, and some kind of rock with small distribution such as: porphyritic biotite granite, granosyenite, olivine gabbro, gabbro diabase, conga diabase... The ages of rocks vary from Proterozoic to Trias. The bedrock of this study area is weathered strongly, the average thickness of weathered layer is 3 - 5 meters, and the most thickness layer is 20 meters as observed in the cut slopes along the transportation road in the region.

The contact between bedrock and weathering soils is often exposed in the cuts slopes, which make them more susceptible to landslides due to the build-up of pore pressure on the contact [10] [11]. Moreover, weathering alters the mechanical, mineralogic and hydrologic attributes of the regolith, and, hence, is an important factor of slope instability in many settings [23].

The land use of the study area comprises of forest land, barren land and non-forest rocky mountain, agricultural land, residential areas, bush and grass areas and water surface.

The study area is situated in the monsoonal region, with four seasons. The coldest month is January and the hottest month is June with average temperature of $14^{\circ} \mathrm{C}$ and $27^{\circ} \mathrm{C}$, respectively. Seasons in the region can be classified as rainy and dry. Rainfall is main occurs in rainy season. According to the National Centre for Hydro-meteorological Forecasting of Vietnam recorded from 1957 to 
2013, the average annual rainfall of this area ranging from 2500 to $3300 \mathrm{~mm} /$ year where $90 \%$ of the total rainfall occurs in the summer (from May to October every year). Moreover, the frequency and intensity of the rainfall are concentrated over a short period that triggers most of the disastrous hazards in the study area.

\subsection{Landslide Database}

Landslide database was collected from historical records of the previous projects. This data is based on landslide inventory from several projects such as: 1) "Investigation and assessment of the types of geological hazard in the territory of Vietnam and recommendation of remedial measures". Phase II: A study of the northern mountainous province of Vietnam [24];2) "The report of investigation of natural hazards in the northwest of Vietnam" [25]; 3) "Status geo-hazards assessment in four mountainous provinces in North of Vietnam: Ha Giang, Tuyen Quang, Cao Bang, Bac Kan. Defining sources, prediction and propose preventive measures and consequences mitigation" [26]; 4) "The State-Funded Landslide Project" is a national program to systematically assess landslide susceptibility, hazard and risk for all of prone areas in Vietnam. The first phase of the project (2012-2014) some activities of landslide inventory mapping were implemented over the fourteen Northern mountainous provinces [27].

In the study area numerous landslides normally occur in the period from May to October. However, almost of landslide points which were collected from field work of previous projects are lacked of exactly dates of landslide occurrence. Some difficulties was mentioned by Hung [27] such as: few or no sources of historic information due to the isolated sites or little memory of small or medium size events; no updates developed by the surveyors after they finished their tasks. These problems caused a lot of difficulties when using landslide database for analyzing the relationship between rainfall evens in the past with historical landslide records. Figure 2 shows the landslide distribution in Ha Giang city and the surroundings. This landslide inventory map was established based on the landslide database collected from the projects was mention above. The total of landslides in the study area are 245 points, landslides are mostly shallow rotational slides with 107 points, the next type of movement is complex slides with 70 points, the shallow translational debris slides with 53 points, debris flows with 9 sites and finally is topple with 6 sites. The minimum size of landslides is $40 \mathrm{~m}^{3}$ and the maximum size is $9450 \mathrm{~m}^{3}$ and median $=134 \mathrm{~m}^{3}$ and the total of volume of landslides is approximately $150.000 \mathrm{~m}^{3}$ but this type of natural disaster have been increasingly severe in term of magnitude, frequency and volatility, causing vast losses in human life, property, socio-economic and cultural infrastructure as well as environmental degradation. As a mention above, most of the landslides are undefined landslides it means that the surveyor could not collected the exactly date of landslide initiation. Fortunately, from historical landslide records we had list of 37 landslide events that knew exactly when landslide occurred. Inside, 26 landslide-triggering events occurred from 1989 to 2009 and the 


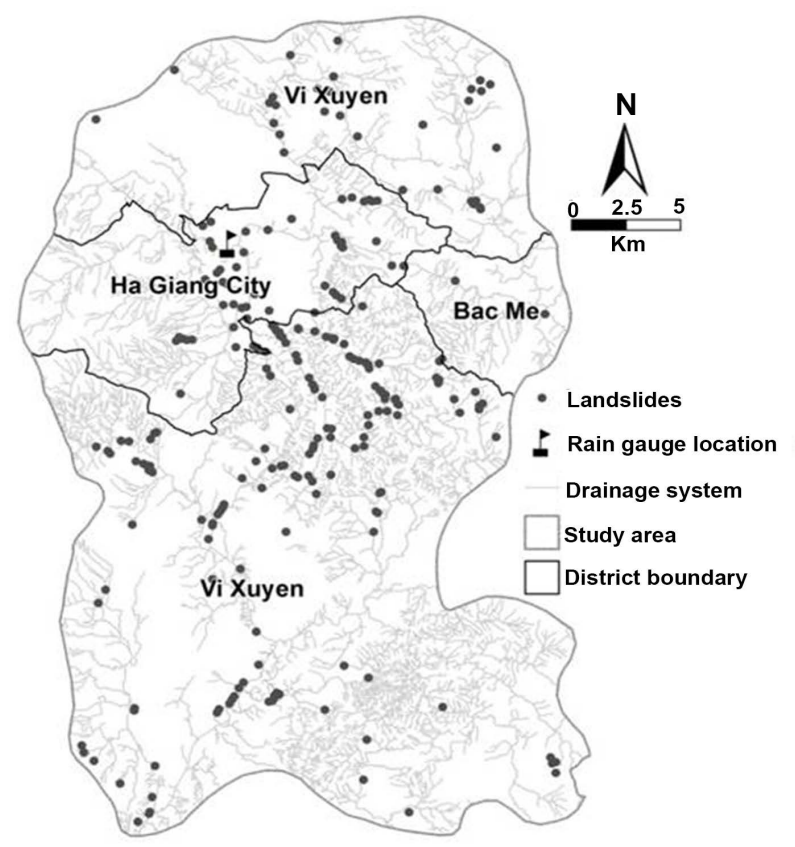

Figure 2. Map showing location of landslides, rain gauges and the drainage system of the study area.

remaining 11 events occurred in 2013. Most of landslides occurred in July with 20 events, the next is in June with 10 events, both of May and August are having the same times with 3 events, and then in September with 1 events. Analysis of the landslide inventories shows that most of the slope failures in the study area were caused by rainfall infiltration into the soil causing an increase in soil pore-water pressure [24] [26].

\subsection{Rainfall Database}

For the study area, daily rainfall data were collected from a unique rain gauge belonging to the National Centre for Hydro-meteorological Forecasting of Vietnam from the period of time 1957 to 2013. The location of this rain gauge is shown in Figure 2 and some features of rainfall data is shown in Figure 3.

The total of yearly rainfall of study area was from 1957 to 2013 ranging from 2500 to 3300 . The study of daily rainfall records reveals that the area experiences rainfall in two periods: rainy season, that the rainfall is always concentrate in May to October and the common highest month of rainfall is often July and dry season from November to April. The lowest recorded annual rainfall is $1465 \mathrm{~mm}$ and the highest is $3305 \mathrm{~mm}$ (Figure 3(a)). The minimum of total number of days with recorded rainfall is 153 days and the maximum of it is 209 days (Figure 3(d)). The maximum daily rainfall during in rainy season varies from $67.6 \mathrm{~mm}$ to $256.2 \mathrm{~mm}$ (Figure 3(b)). During 57 years (from 1957 to 2013) the most common month that occurred maximum daily rainfall most frequently is July with 20 times, the second is August with 15 times, the third is June with 12 times, May with 7 times and September, October and December is the same with 1 times (Figure 3(c)). 


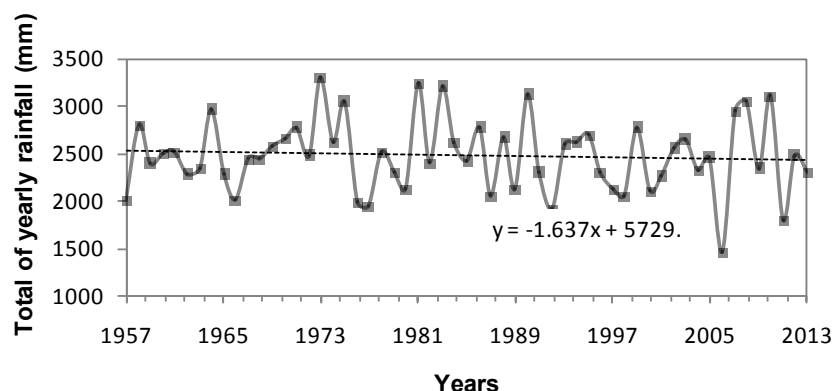

(a)

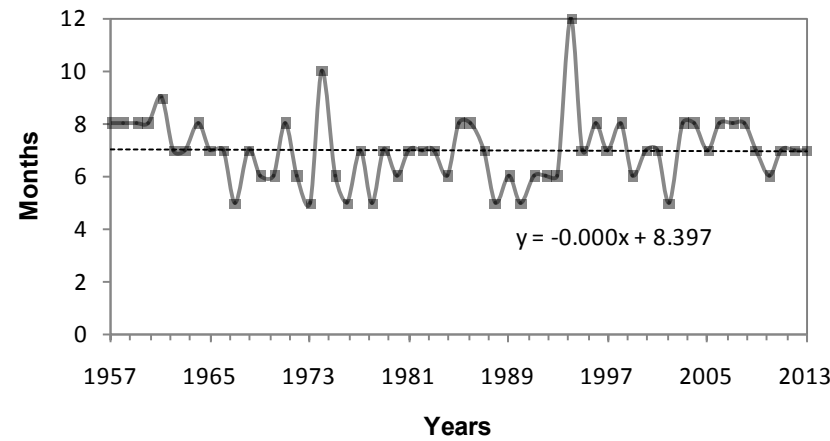

(c)

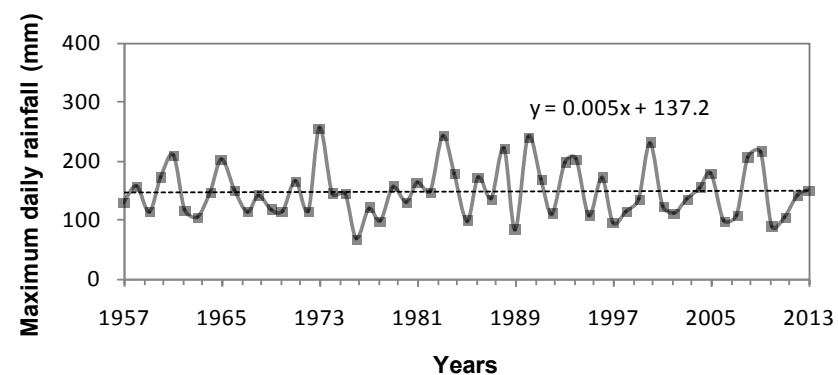

(b)

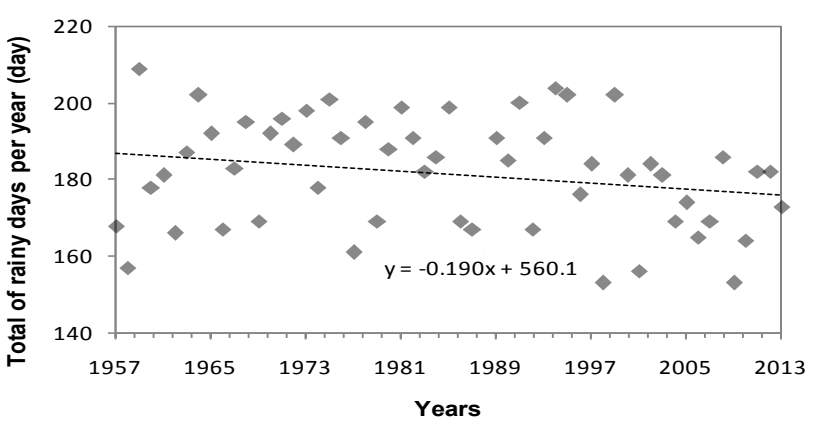

(d)

Figure 3. Some characteristics of rainfall data in the study area from 1957 to 2013 and trend lines. (a) The average annual rainfall; (b) Maximum daily rainfall; (c) The months happened maximum daily rainfall; (d) Total of rainy days per year.

Although in Vietnam, many landslide project have been completed during 20 recent years but we are really lack of some important information of historical landslide data. The first reason of this fact is because all the landslide field work of the previous projects was carry out in April or October. April is at the end of period of time of dry season and October is at the end of period of time of rainy season. This works is not suitable for collecting the landslide information because almost of landslide in mountainous area of Vietnam is always occurs in rainy season from May to October, especially this natural phenomenon is occurred with the most frequently in 3 months from June to August. Due to the fact that, the landslide information collected is very hard to link with exactly date of rainfall episode. Although in the study area collected 245 landslides but most of them could not define the exactly date except 37 landslides triggering events as mention above. Most of these landslides have occurred in areas where the rainfall was relatively high with average daily rainfall occurred landslide is more than $76 \mathrm{~mm}$, even having 9 of 37 landslides occurred the same day with maximum daily rainfall.

\section{Probability of Occurrence of the Triggering Rainfall Threshold}

\subsection{Determination of the Rainfall Threshold}

One of the most difficulties when using antecedent rainfall measurements to predict landslide occurrence is the definition of the period over which to accu- 
mulate the precipitation [6] [22].

A detailed literature review revealed a complex relationship on the correlation between numbers of days for the antecedent rainfall with the triggering of a landslide [22]. The days for antecedent rainfall have mentioned in many previous studies [1] [4] [6] [9] [10] [11] [28] [29] have attempted to establish rainfall-intensity thresholds so that slope failure predictions could be made accurately. These various works define rainfall threshold in terms of rainfall intensity, duration vs. intensity ratio, cumulative rainfall in a given time, antecedent rainfall vs. daily rainfall ratio, event rainfall vs. yearly average rainfall ratio, and daily rainfall vs. antecedent excess rainfall ratio [29].

The thresholds using rainfall intensity-duration are the most widely used method in the literature [30]. For rainfall threshold estimation, the most four common variables used in the literature are as follows: daily rainfall [9], antecedent rainfall [9] [10] [11], cumulative rainfall [28], and normalized critical rainfall [4]. In general, the selection of the right parameters in constructing rainfall threshold is mainly dependent on the landslide type [30].

In this study area where daily rainfall (covering a time span of 57 years from 1957 to 2013) and hourly rainfall data (only from May to October in the period of 4 years from 2010 to 2013) are available, so antecedent rainfall plays an important role in estimation of landslide initiation introduced by Jaiswal and Van Westen [11] is applied in this paper.

As discussed in Section 2, landslide hazard in the area having strong relationship with certain intensity of rainfall. Hence, we suppose that the probability of occurrence of a landslide is related to the probability of occurrence of the triggering rainfall threshold. It means that landslide has to occur whenever a given rainfall threshold is exceeded may not hold always and everywhere. However, it is also expected that landslides will not occur below the rainfall threshold. Hence, for rainfall-triggered landslides, this assumption can be an acceptable first-approximation to work with and to estimate the frequency of landslides by establishing relations between the landslide trigger, its magnitude and the occurrence of the landslides [11].

Depending on the type of landslides and their geo-environmental setting, the number of antecedent days can vary from 3 days for shallow landslides to 30 days for deep landslides [4] [10] [11]. In order to determine the suitable number antecedent days required for shallow landslides of the study area, we selected 29 landslide-triggering events (in total 37 landslide-triggering events have mentioned in Section 2.1) that have occurred between 1989 and 2013 in this area. After analyzing the $3,5,7,10$, and 15-day antecedent rainfall, according to the method suggested by [10], the 3-day antecedent rainfall was considered suitable for the analysis.

\subsection{Results}

To determine the rainfall threshold $\left(\mathrm{R}_{\mathrm{T}}\right)$, a scatter plot was prepared showing daily rainfall against the corresponding 3-day antecedent rainfall, for each day 
with one or more triggered shallow landslides. The envelope curve is manually drawn such that it demarcates the lower end of the plotted points. The line can be represented by a linear mathematical equation [3] [11].

In this study area, $R_{T}$ above which a landslide can occur for the given 3-day antecedent rainfall $\left(R_{3 a d}\right)$ is represented by the equation $R_{T}=40.8-0.201 R_{3 a d}$. Besides, we also established the equations of rainfall threshold for 5, 7, 10 and 15-day antecedent rainfall and the landslides that occurred in study area were used for the threshold validation (Figure 4).

In some cases, landslides were also occurred in the days which no rainfall or with very few of daily rainfall was measured. These were the cases when high antecedent rainfall alone has resulted in landslides and other reason is the failures to pore pressure rising due to water percolating from upslope areas. This holds for landslides associated with cut slopes because during excavation toe of such slopes are removed and the unsupported overburden mass becomes more prone to failure under the given condition. Thus, for all the listed thresholds, the lower boundary of the envelope curve was set to zero daily rainfall [11].

\subsection{Validation of Rainfall Threshold Model}

The rainfall thresholds can be used to predict landslides both spatially and temporally. The temporal aspect is related to the daily variations in rainfall and the spatial aspect can be related to the use of different thresholds for different areas. An indirect way to test the predicting capability of the thresholds is to validate them with the control data sets, which were not used in the model [11].

In order to validate the model, the historical landslide recorded in some years such as 2000, 2007, 2008, and 2013 were used. A part of the landslide events in these years were also used in the rainfall threshold model creation. Figure 5 shows the results of validation of rainfall threshold model of the study area.

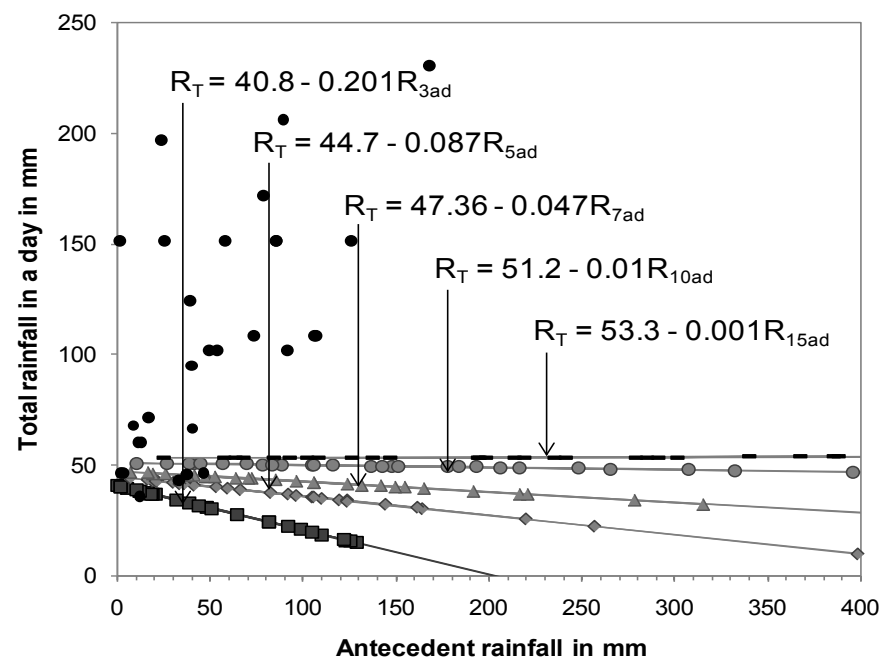

Figure 4. Rainfall thresholds for the study area, $R_{T}$ is the threshold rainfall and $R_{3 a d}, R_{5 a d}, R_{7 a d}, R_{10 a d}$ and $R_{15 a d}$ are the different of antecedent rainfall days and black points are the landslides were used for the threshold validation. 


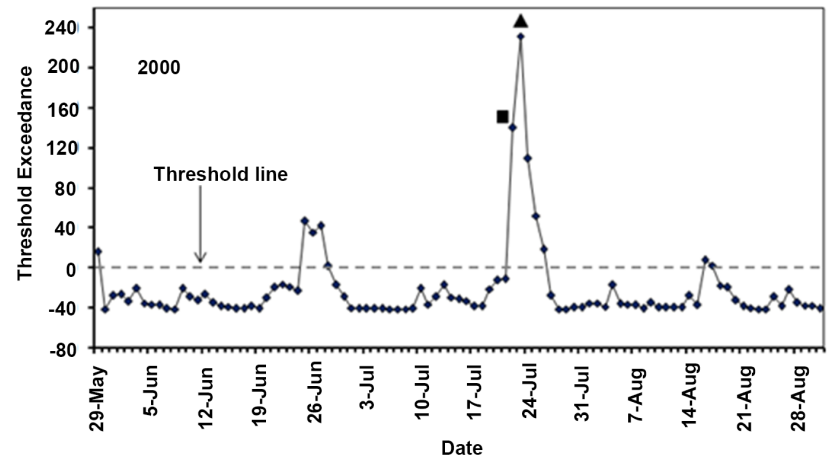

(a)

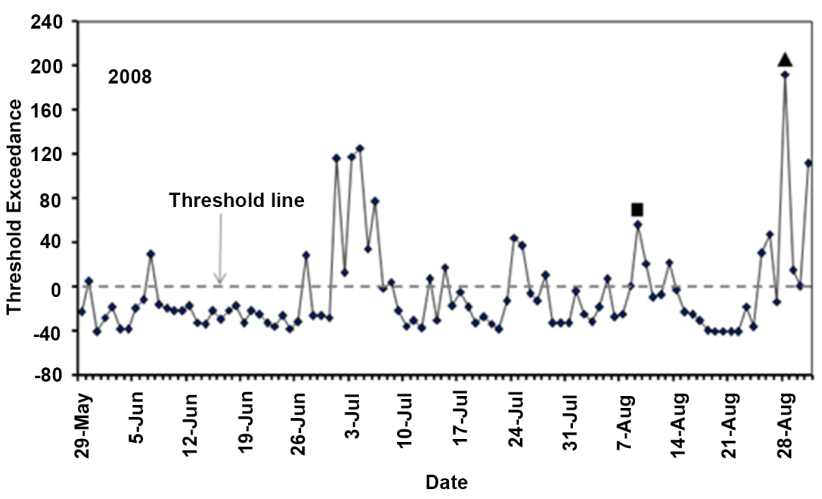

(c)

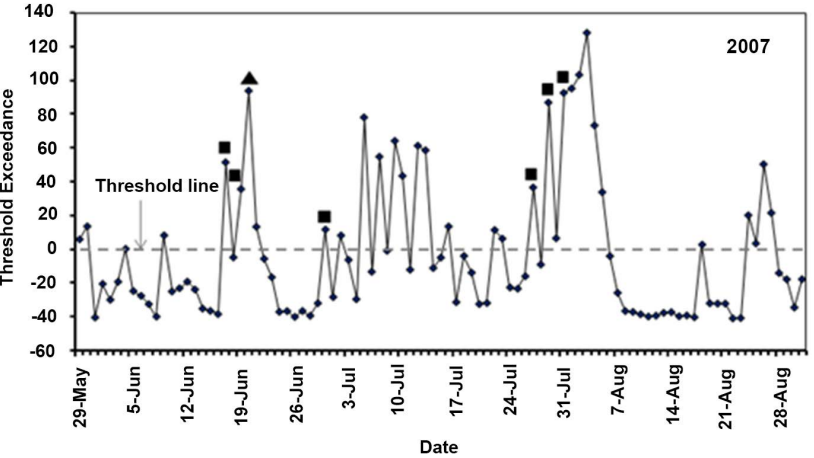

(b)

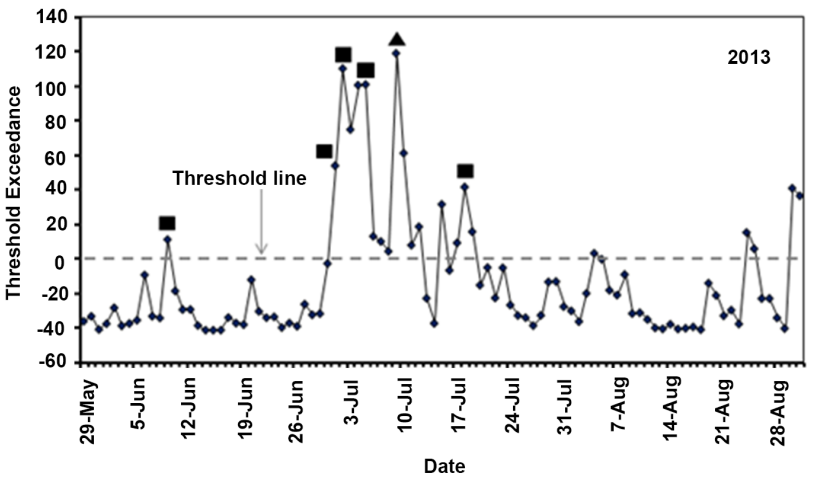

(d)

Figure 5. Validation of the threshold equation $\mathrm{R}_{\mathrm{T}}=40.8-0.201 \mathrm{R}_{3 \mathrm{~d}}$ for the study area. Validation was done for the year 2000 , 2007, 2008 and 2013. Positive values on the vertical axis indicate threshold exceedance $\left(R>R_{T}\right)$. Black squares indicate the dates of landslide-triggering rainfall events considered in the model. Black triangles are the event dates that were not considered in building the threshold model.

According to the results shows in Figure 5, in the period from 29 May to 31 August 2000, the rainfall threshold exceed 10 times and landslides occurred in the day that happened maximum daily rainfall in July and in the day having the second high of rainfall of the month as well. And in the 2007 witnessed many times the rainfall has exceeded the threshold curve. It was also one of the years having high average rainfall in the rainy season, especially in July with more than $1000 \mathrm{~mm}$. In 2008 and 2013 was also recorded a lot of rainfall events exceed the threshold rainfall. Compare to 2000, the number of times which rainfall threshold exceed in the 2007, 2008 and 2013 were much more. Perhaps, it represented for extreme-weather condition influenced by global climate changes.

\section{Bayesian Probability Model}

Bayesian subjective probability models, forecasting models can be constructed using statistical methods applied to objective data. However, when historical data are unavailable, irrelevant, or there are time and financial restrictions, a subjective approach can be used. The Bayesian subjective probability model relies on querying the opinions and intuitions of a group of experts, obtaining probability estimates, and processing them through the Bayes formula. It should be 
noted that subjective models are limited in that they are slow in revealing previously unrecognized relationships. Experts can err in making complex forecasts, especially if they have to consider conflicting clues. "Clues" are defined as separate independent facts that impact on the forecast. Because the number and form of clues varies, it is therefore important to aid the experts' judgments with a methodology to organize them. The Bayes probability model provides a structure for breaking a complex judgment into several smaller components and reducing expert error. Construction of the Bayes probability model requires four steps: 1) Decide on events to forecast; 2) Identify the clues; 3) Assess likelihood estimates; 4) Use Bayes formula to forecast [31].

\subsection{One-Dimensional Case}

Because of only have a unique rain gauge in the study area, so we selected Bayesian probability model applied for one-dimensional case to calculate landslide probability caused by daily rainfall (mm/day). According to Berti [21], Bayes' theorem can be presented as below.

Bayes' theorem is a direct application of conditional probabilities. The conditional probability is the probability of some event A (in our case a landslide) given the occurrence of some other event $B$ (a rainfall episode with a certain magnitude, expressed in terms of total rainfall, intensity or any other variable). Conditional probability is written $P(A \mid B)$ and it is read "the probability a landslide $(A)$ occurs given a rainfall episode $(B)$ ". This probability is provided by the Bayes' theorem:

$$
P(A \mid B)=\frac{P(B \mid A) \cdot P(A)}{P(B)}
$$

where:

$P(B \mid A)=$ conditional probability of $B$ given $A$ (also called the likelihood), that is the probability of observing a rainfall event of magnitude $B$ when a landslide occurs,

$P(A)=$ prior probability of $A$ (or simply prior), that is the probability a landslide occurs regardless of whether a rainfall event of magnitude $B$ occurs or not,

$P(B)=$ marginal probability of $\mathrm{B}$, that is the probability of observing a rainfall of magnitude $\mathrm{B}$ regardless of whether a landslide occurs or not,

$P(A \mid B)=$ conditional probability of $A$ given $B$ (also called posterior probability), that is the probability of observing a landslide when a rainfall event of magnitude B occurs.

Bayesian probability is usually computed in terms of relative frequencies. Thus, if $N_{R}$ is the total number of rainfall events recorded during a given time reference; $N_{A}$ is the total number of landslides occurred during the same period; $\mathrm{N}_{\mathrm{B}}$ is the number of rainfall events of magnitude $B$; and $N_{(B \mid A)}$ is the number of rainfall events of magnitude $B$ that resulted in landslides, the probability terms in (1) can be approximated to: 


$$
\begin{gathered}
P(A) \approx N_{A} / N_{R} \\
P(B) \approx N_{B} / N_{R} \\
P(B \mid A) \approx N_{(B \mid A)} / N_{A}
\end{gathered}
$$

And Equation (1) reduces to $P(A \mid B) \approx N_{(B \mid A)} / N_{B}$.

\subsection{Two-Dimensional Case}

Equation (1) can be easily extended to the case of two variables $B$ and $C$ :

$$
P(A \mid B, C)=\frac{P(B, C \mid A) \cdot P(A)}{P(B, C)}
$$

where: the notation $B, C$ indicates the joint probability of having a certain value (or range of values) of the two variables. If, for example, $B \equiv I$ is rainfall intensity and $C \equiv D$ is rainfall duration, Equation (3) provides the probability of a landslide in response to a rainfall event of given duration and intensity.

In this paper, we selected Bayesian probability model applied for two-dimensional case to calculate landslide probability caused by two factors, rainfall intensity $(\mathrm{mm} /$ day) and rainfall duration (days).

\subsection{Identification of Rainfall Events}

According to Driver [31], construction of the Bayes probability model requires four steps and the first step is "decide on events to forecast".

The first step in the evaluation of any rainfall threshold is to identify the rainfall episodes that triggered the historical landslides, here referred as "triggering rainfall". Ideally a triggering rainfall event should be a well-defined rainfall episode, described by its duration, amount of precipitation, and intensity and clearly related to a given landslide. In some cases the identification is simple (for instance if the landslide occurred after a heavy rainfall preceded by a prolonged dry period) but usually it is not. Landslides may result from complex rainfall sequences made of multiple bursts of variable duration and intensity that make it difficult to detect a well-defined triggering episode. The greatest uncertainties usually derive from the identification of the beginning of the triggering rainfall while the time of landsliding is taken as its end. A certain amount of time without rainfall (or limited rainfall) can be used as criterion to truncate the rainfall sequence that precedes a landslide event [21] [32].

In this paper, we concentrated on estimating the probability of rainfall threshold for landslide occurrence using daily rainfalls as the triggering rainfall events. For each of the 37 historical landslides (see 2.1), we compared the rainfall data recorded by the reference rain gauge with those recorded. This work was done to find out the relationship between rainfall cumulative data with landslide occurrence in the past events. The triggering rainfall was then defined visually by selecting the rainfall episode closest to the date of occurrence of the landslide. The results were then compared and the discrepancies (usually related to the beginning of the triggering event) were discussed to arrive at a shared definition. 
We generally agreed to define the triggering event as a period of continuous or nearly continuous precipitation which starts with the onset of the rainfall (or with an abrupt increase of rainfall intensity in a period of light rain) and ends the day of occurrence of the landslide. For those landslides that have occurred after the end of the rainfall, the duration of the triggering event was set equal to the rainfall duration [21].

Based on the classification of Berti [21], each triggering rainfall was then classified as 3 types: well-defined (type 1), uncertain (type 2), or undefined (type 3).

Type 1: Well-defined rainfall events can be clearly identified, as shown in the examples of Figure 6 (Type 1 Well-defined).

Type 2: Uncertain events consist of distinct rainfall episodes characterized by uncertain or subjective limits because of the presence of secondary rainfall episodes (Figure 6, Type 2 Uncertain).

Type 3: Undefined events consist of all those landslides without a significant rainfall event close to the date of occurrence, such as landslides triggered during complex rainfall sequences (Figure 6, Type 3 Undefined). The difficulty to establish the exact time of a landslide [6] and the influence of factors other than rainfall are of the main reasons for these undefined events.

\subsubsection{One-Dimensional Case}

In order to calculate the values of $P(A), P(B), \mathrm{P}(B \mid A), P(A \mid B)$ we selected only well-defined events (Type 1) for considering in Bayesian analysis. When using this method trigger rainfall must be reliably identified in order to get a reliable likelihood function $P(B \mid A)$. Landslides triggered by other factors (Type 2 and 3) were then omitted [21].

Among 37 landslides triggered by rainfall events in the study area, we selected 26 well-defined rainfall events for the input data for Bayesian approach.

The analysis can be applied to the study area data set following the procedure described in Section 4.2.

The marginal rainfall probability $P(B)$ is computed using the $N_{R}=346$ rainfall events recorded (we only used rainfall data in the months that occurred landslide triggering rainfall events) in the period of 13 years (May of 1989; May and June of 1993; June of 1995; August of 1996 and 2008; July of 1997, 1998, 2000, 2001, 2004 and 2009; June and July of 2006; June, July and September of 2007). The conditional probability $P(A \mid B)$ using the $N_{A}=26$ well-defined rainfall that triggered the historical landslides. Prior landslide probability is therefore $P(A)=N_{A} / N_{R}=26 / 346=0.08$. In Table 1 shows the database of the study area which used to calculate the values of probability $P(A), P(B \mid A), P(B)$ and $P(A \mid B)$ and the Table 2 shows the results after calculating. After that, we plotted the graphs to express the comparison of landslide probability $P(A)$, prior rainfall probability $P(B)$ and conditional probability $P(B \mid A)$ (Figure 7(a)) and computed values of conditional landslide probability $P(A \mid B)$ with each classification of rainfall events (Figure 7(b)) as well.

Due to lack of historical landslide records in three years, 2010, 2011 and 2012, we decided not using the landslide database of 2013. This data will be combined 

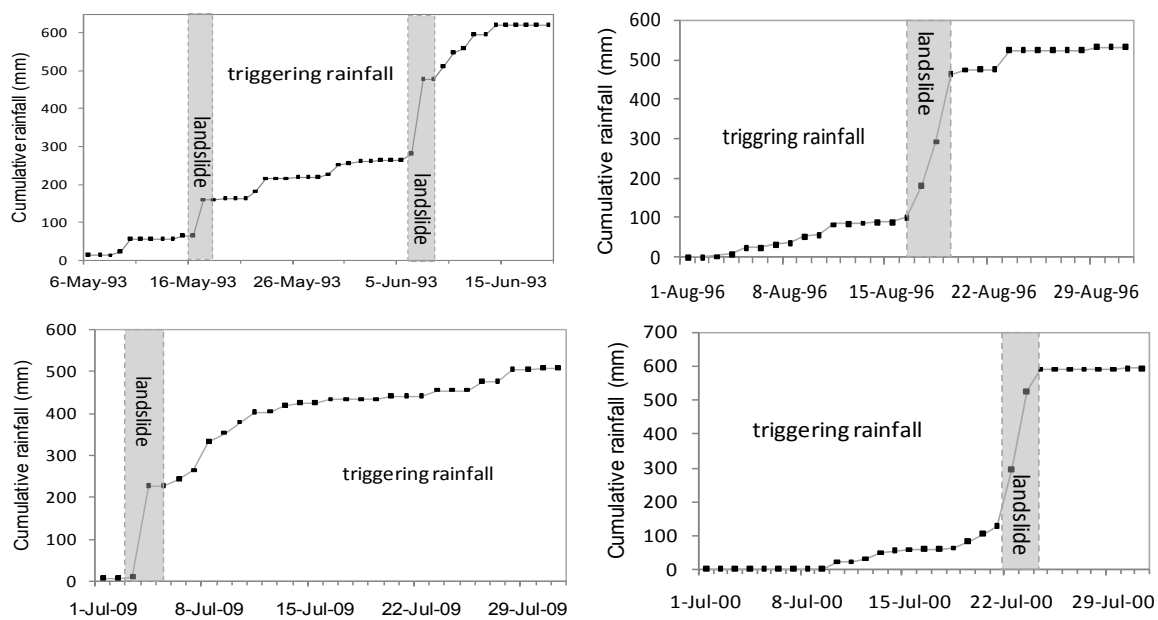

(a)
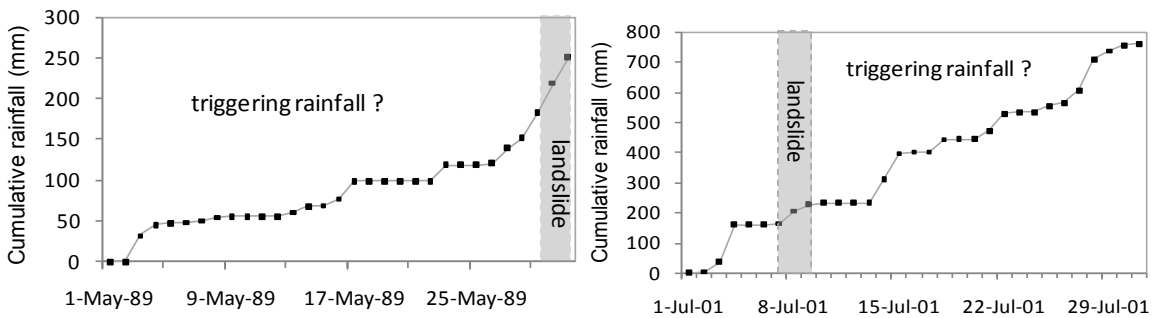

(b)
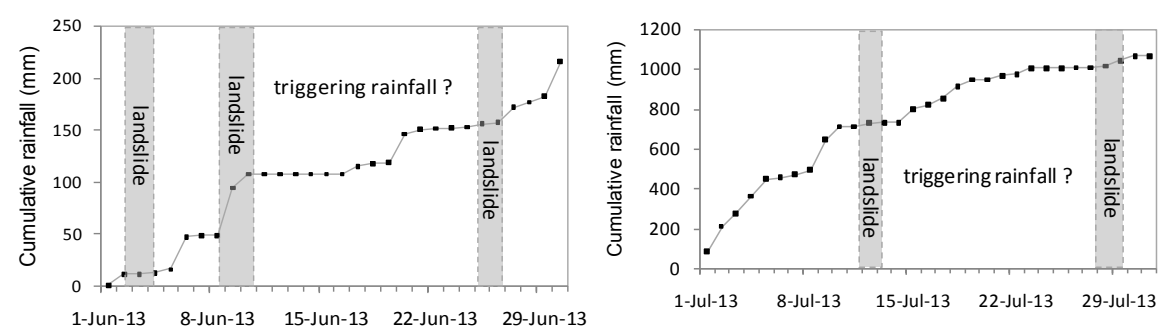

(c)

Figure 6. Some selection of triggering rainfall types based on cumulative rainfall in study area. (a) Type 1: Well-defined; (b) Type 2: Uncertain; (c) Type 3: Undefined.

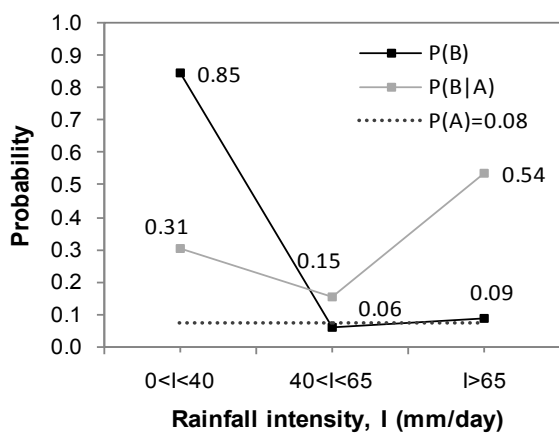

(a)

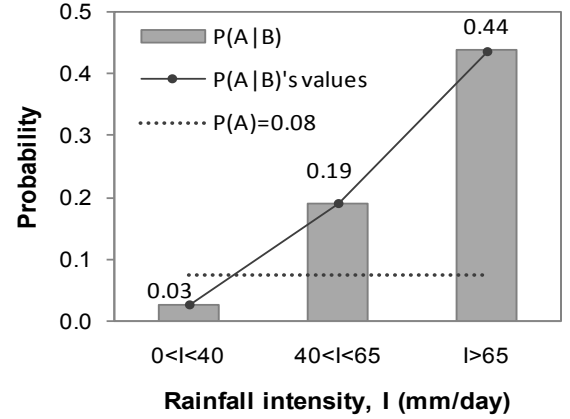

(b)

Figure 7. One-dimensional Bayesian analysis in the period of 13 years of the study area: (a) Comparison of prior landslide probability $P(A)$, prior rainfall probability $P(B)$, and conditional probability $P(B \mid A)$ for three different classes of rainfall intensity; (b) Computed values of conditional landslide probability $P(A \mid B)$ and comparison with prior landslide probability $P(A)$. 
Table 1. The information about the landslide events, total of rainfall events in 13 years and the classification of calculated thresholds for daily rainfall intensity data.

\begin{tabular}{|c|c|c|c|c|c|c|c|}
\hline $\begin{array}{l}\text { Total } \\
\text { rainfall } \\
\text { events }\end{array}$ & $\begin{array}{l}\text { Number of daily } \\
\text { rainfall intensity with } \\
0<\mathrm{I}<40 \mathrm{~mm} \text { /day }\end{array}$ & $\begin{array}{c}\text { Number of } \\
\text { landslide with } 0 \\
<\mathrm{I}<40 \mathrm{~mm} / \text { day }\end{array}$ & $\begin{array}{l}\text { Number of daily } \\
\text { rainfall intensity with } \\
40<\text { I }<65 \mathrm{~mm} \text { /day }\end{array}$ & $\begin{array}{c}\text { Number of } \\
\text { landslide with } 40< \\
\mathrm{I}<65 \mathrm{~mm} / \text { day }\end{array}$ & $\begin{array}{l}\text { Number of daily } \\
\text { rainfall intensity } \\
\text { with } \mathrm{I}>65 \mathrm{~mm} / \text { day }\end{array}$ & $\begin{array}{c}\text { Number of } \\
\text { landslide with } \\
\mathrm{I}>65 \mathrm{~mm} / \text { day }\end{array}$ & $\begin{array}{c}\text { Total } \\
\text { landslide }\end{array}$ \\
\hline 346 & 293 & 8 & 21 & 4 & 32 & 14 & 26 \\
\hline
\end{tabular}

Table 2. The probability values of one-dimensional Bayesian analysis that calculated based on daily rainfall intensity of the study area in the period of 13 years.

\begin{tabular}{|c|c|c|c|c|c|c|c|}
\hline $\begin{array}{l}\text { Rainfall intensity } \\
\text { classification }\end{array}$ & $\begin{array}{c}\text { Rainfall } \\
\text { events }\end{array}$ & $P(B)$ & $P(B \mid A)$ & $P(A)$ & $\begin{array}{l}\text { Probability } \\
\mathrm{P}(A \mid B)\end{array}$ & $\begin{array}{c}\text { Total } \\
\text { landslide }\end{array}$ & $\begin{array}{l}\text { Total rainfall } \\
\text { events }\end{array}$ \\
\hline $0<\mathrm{I}<40$ & 293 & 0.85 & 0.31 & 0.08 & 0.03 & & \\
\hline $40<\mathrm{I}<65$ & 21 & 0.06 & 0.15 & 0.08 & 0.19 & 26 & 346 \\
\hline $\mathrm{I}>65$ & 32 & 0.09 & 0.54 & 0.08 & 0.44 & & \\
\hline
\end{tabular}

with two types of rainfall data that are daily rainfall and hourly rainfall for estimating the values of probabilities in two ways one-dimensional and two-dimensional Bayesian analysis for only 2013. The results of one-dimensional Bayesian analysis shows in Table 3, Table 4 and Figure 8, and the results of two-dimensional Bayesian analysis will be presented in Section 4.4.2.

\subsubsection{Two-Dimensional Case}

Two-dimensional Bayesian analysis evaluates the conditional probability of the event given the joint occurrence of two control variables (Section 4.2).

In order to calculate the values of probability in two-dimensional Bayesian probability model requires the data collection in more detail and based on the rainfall intensity and duration. Because of the hourly rainfall data are not frequently available especially for a long period of time in the past. Therefore, we only had collected this type of data in 4 years, from 2010 to 2013 in 6 months of rainy seasons (from May to October). Although, our landslide database be collected to 2013 but these are unavailable in during three years from 2010 to 2012. So that, we have to be use the landslide data in three months, from May to July of 2013 for calculating the parameters of two-dimensional Bayesian probability model.

The application of probability model follows the Equation (3) described in Section 4.2. The hourly rainfall events recorded in three months of May, June and July in 2013 was 68 events, the total landslide events occurred was 11, total duration happened total rainfall events was 18.46 days (shortest duration was 0.04 day/a rainfall event, and the longest duration was 0.67 day/a rainfall event). To evaluate the conditional probability of the event given the joint occurrence of two control variables are hourly rainfall events and its duration, we classified "rainfall intensity-rainfall duration, I-D" into four categories for calculating easily. Four different combination of rainfall intensity and duration of study area classified basing on the equation of probability of occurrence of the triggering 
Table 3. The information about the landslide events, total of rainfall events in June and July of 2013 and the classification of calculated thresholds for daily rainfall intensity data.

\begin{tabular}{|c|c|c|c|c|c|c|c|}
\hline $\begin{array}{l}\text { Total } \\
\text { rainfall } \\
\text { events }\end{array}$ & $\begin{array}{l}\text { Number of daily } \\
\text { rainfall intensity with } \\
0<\mathrm{I}<40 \mathrm{~mm} \text { /day }\end{array}$ & $\begin{array}{c}\text { Number of } \\
\text { landslide with } 0 \\
<\mathrm{I}<40 \mathrm{~mm} / \text { day }\end{array}$ & $\begin{array}{c}\text { Number of daily } \\
\text { rainfall intensity } \\
\text { with } 40<\mathrm{I}<65 \\
\mathrm{~mm} / \text { day }\end{array}$ & $\begin{array}{c}\text { Number of } \\
\text { landslide with } 40< \\
\mathrm{I}<65 \mathrm{~mm} / \text { day }\end{array}$ & $\begin{array}{c}\text { Number of daily } \\
\text { rainfall intensity } \\
\text { with } \mathrm{I}>65 \\
\mathrm{~mm} / \text { day }\end{array}$ & $\begin{array}{l}\text { Number of } \\
\text { landslide with } \\
\mathrm{I}>65 \mathrm{~mm} / \text { day }\end{array}$ & $\begin{array}{c}\text { Total } \\
\text { landslide }\end{array}$ \\
\hline 51 & 40 & 3 & 5 & 3 & 6 & 4 & 10 \\
\hline
\end{tabular}

Table 4. The probability values of one-dimensional Bayesian analysis that calculated based on daily rainfall intensity of the study area in June and July of 2013.

\begin{tabular}{cccccccc}
\hline $\begin{array}{c}\text { Rainfall intensity } \\
\text { classification }\end{array}$ & $\begin{array}{c}\text { Rainfall } \\
\text { events }\end{array}$ & $P(B)$ & $P(B \mid A)$ & $P(A)$ & $\begin{array}{c}\text { Probability } \\
P(A \mid B)\end{array}$ & $\begin{array}{c}\text { Total } \\
\text { landslide }\end{array}$ & $\begin{array}{c}\text { Total rainfall } \\
\text { events }\end{array}$ \\
\hline $0<\mathrm{I}<40$ & 40 & 0.78 & 0.30 & 0.20 & 0.08 & & 51 \\
$40<\mathrm{I}<65$ & 5 & 0.10 & 0.30 & 0.20 & 0.60 & 0.67 & \\
$\mathrm{I}>65$ & 6 & 0.12 & 0.40 & 0.20 & 0 & \\
\hline
\end{tabular}

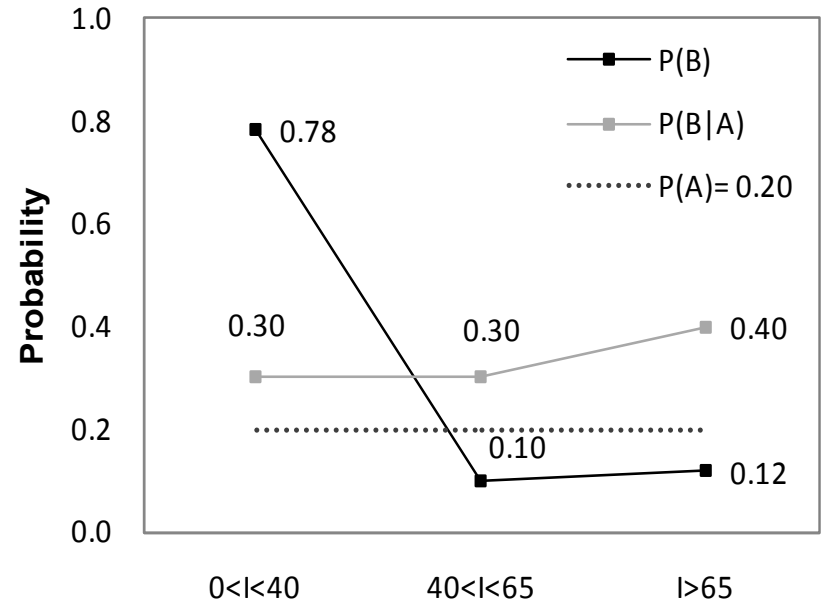

Rainfall intensity, I (mm/day)

(a)

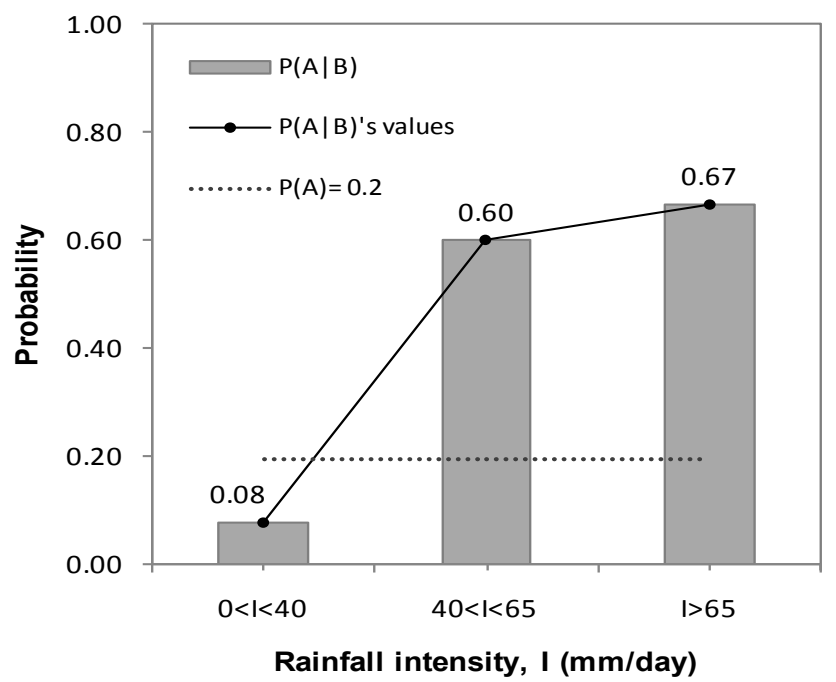

(b)

Figure 8. One-dimensional Bayesian analysis in June and July of 2013: (a) Comparison of prior landslide probability $P(A)$, prior rainfall probability $P(B)$, and conditional probability $P(B \mid A)$ for three different classes of rainfall intensity; (b) Computed values of conditional landslide probability $P(A \mid B)$ and comparison with prior landslide probability $P(A)$.

rainfall threshold of the study area which established in Section 3.2 with $R_{T}=$ $40.8-0.201 \mathrm{R}_{3 \mathrm{ad}}$.

1) Rainfall events has $I \leq 40 \mathrm{~mm} /$ day and $\mathrm{D} \leq 0.3$ day,

2) Rainfall events has $\mathrm{I} \leq 40 \mathrm{~mm} /$ day and $\mathrm{D}>0.3$ day,

3) Rainfall events has I $>40 \mathrm{~mm} /$ day and $\mathrm{D} \leq 0.3$ day, and

4) Rainfall events has $\mathrm{I}>40 \mathrm{~mm} /$ day and $\mathrm{D}>0.3$ day.

Based on Table 5, we calculated the values of $P(I \mid D), P(I, D \mid A), P(A)$ and $P(A \mid I, D)$ and expresses in Table 6. The 3D bars of the conditional landslide probability for four different combinations of rainfall intensity and rainfall duration shows in Figure 9. 
Table 5. Rainfall intensity-duration that did and did not result in landslides in May, June and July in 2013.

\begin{tabular}{|c|c|c|c|c|c|}
\hline $\begin{array}{l}\text { Classification of rainfall } \\
\text { intensity-duration (RID) }\end{array}$ & $\begin{array}{l}\text { RID did result in } \\
\text { landslides }\end{array}$ & $\begin{array}{l}\text { RID did not result in } \\
\text { landslides }\end{array}$ & $\begin{array}{c}\text { Total of RID events of } \\
\text { each class }\end{array}$ & $\begin{array}{c}\text { Total of landslide } \\
\text { events }\end{array}$ & $\begin{array}{c}\text { Total of RID } \\
\text { events }\end{array}$ \\
\hline $\mathrm{I} \leq 40 \& \mathrm{D} \leq 0.3$ & 4 & 39 & 43 & \multirow{4}{*}{11} & \multirow{4}{*}{68} \\
\hline $\mathrm{I} \leq 40 \& \mathrm{D}>0.3$ & 2 & 12 & 14 & & \\
\hline $\mathrm{I}>40 \& \mathrm{D} \leq 0.3$ & 0 & 0 & 0 & & \\
\hline $\mathrm{I}>40 \& \mathrm{D}>0.3$ & 6 & 5 & 11 & & \\
\hline
\end{tabular}

Table 6. The probability values of two-dimensional Bayesian analysis that calculated based on rainfall intensity and duration of the study area in May, June and July in 2013.

\begin{tabular}{|c|c|c|c|c|c|c|}
\hline $\begin{array}{l}\text { Classification of rainfall } \\
\text { intensity-duration (RID) }\end{array}$ & $P(I \mid D)$ & $P(I, D \mid A)$ & $P(A)$ & $P(A \mid I, D)$ & $\begin{array}{c}\text { Total of landslide } \\
\text { events }\end{array}$ & $\begin{array}{c}\text { Total of RID } \\
\text { events }\end{array}$ \\
\hline $\mathrm{I} \leq 40 \& \mathrm{D} \leq 0.3$ & 0.63 & 0.36 & 0.16 & 0.09 & \multirow{3}{*}{11} & \multirow{3}{*}{68} \\
\hline $\mathrm{I} \leq 40 \& \mathrm{D}>0.3$ & 0.21 & 0.18 & 0.16 & 0.14 & & \\
\hline $\mathrm{I}>40 \& \mathrm{D} \leq 0.3$ & 0.00 & 0.00 & 0.16 & 0.00 & & \\
\hline
\end{tabular}

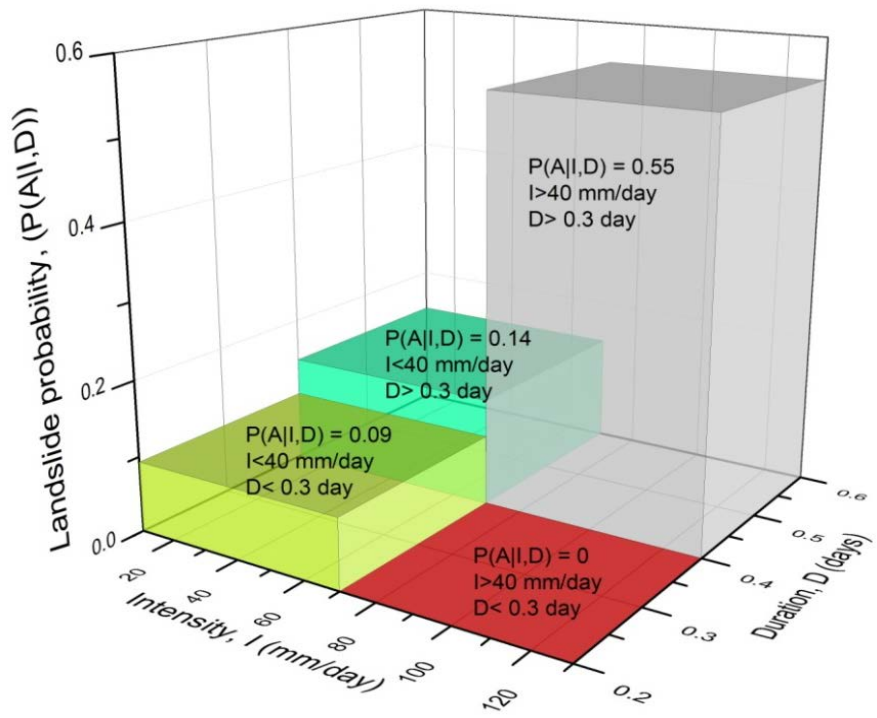

Figure 9. 3D bars of conditional landslide probability for four different combination of rainfall intensity and duration of study area in three months May, June and July in 2013.

\section{Discussion}

According to the main objectives of the paper, we proposed a rainfall threshold model for landslide initiation based on the relationship between the rainfall events and the historical landslide records. Besides this method, a Bayesian approach to estimate the probability of landsliding conditional to characteristics of rainfall events to shows the possible risk of landslide occurrence.

In this paper, a threshold model based on antecedent rainfall have selected, because only daily rainfall data are available for a long time period and easy to 
implement. Data required for the model are derived from the landslide events in the past and daily rainfall records. The selection of the most suitable rainfall threshold model for the study area is based on historical landslide records and daily rainfall records in the period of 13 years, and the works to establish rainfall threshold equations from the relationships of landslides triggered by the rainfall events with antecedent rainfall in 3 days, 5 days, 7 days, 10 days and 15 days. Moreover, a validation of the rainfall threshold was also implemented and the results of this work has supported our selection is appropriate for the study area.

Jaiswal and Van Westen [11] have showed numerous publications on the regionally-derived thresholds of rainfall intensity and duration for landslides are available [7] [29]. Different climatic regions have shown different threshold values for rainfall intensities. Guzzetti [7] have attributed the observed differences may be a direct result of climate on the meteorological conditions that result in shallow hill-slope failures, or an indirect consequence modulated through morphology, soil types, and vegetation cover.

Selection a rainfall threshold method that building based on rainfall intensity and duration for this study area is not suitable because of the limitation of historical landslide records, rainfall records as well as rain gauge station network.

Bayesian probability model applied to calculate the probabilities of landslide occurrence in the study area follow two cases, one-dimensional case and two-dimensional case. In the first case, we determined that the selection of the input data is the most important steps. Therefore, only 26 landslide events in the past selected to take part in the calculation of the model. Beside, the ideal to classify the rainfall intensity threshold applied for the study area was also evaluated carefully basing on the fact of data. According to the rainfall threshold equation that we suggested for the study area in Section 3.2, the classification of rainfall intensity threshold to compute values of conditional landslide probability was applied from this rainfall threshold equation. In the second case, due to the unavailable of hourly rainfall database in the period of 13 years. The application of Bayesian probability model in the case of two-dimensional cannot carry out in this period. Hence, only the hourly rainfall data in May, June and July of 2013 (a unique hourly rainfall data that we collected) was took part in calculating the values of probability of this case. In this area, two variables that used for evaluating of two-dimensional Bayesian probability were rainfall intensity and rainfall duration. The classification of rainfall intensity threshold was also based on the same way in one-dimensional Bayesian probability to compute the values of the conditional probability.

Computed values of conditional landslide probability- $P(A \mid B)$ in one-dimensional case in the period of 13 years in comparison with the values of its in May, June and July of 2013 have the differential levels relative clearly. These differences can explain as a simple way by the unavailable of the database.

Landslides are generally isolated processes which individually may not be very large in size but which can occur with a high frequency in a region. Unlike hazardous events that affect large areas, such as earthquakes or flooding, the gen- 
eration of landslide inventory maps and databases is a tedious procedure. Landslides have to be mapped and described one by one, and each one might have different characteristics. In most countries there is no single agency that has the responsibility for maintaining a landslide database. At best, several organizations, such as the public works department or road department, will deal only with those landslides that have affected their area of interest (e.g., road network), resulting in incomplete and biased databases. Newspaper and other historical records only record those events that caused substantial damage. Universities and research institutes do work on landslide inventory maps but mostly as part of a research project, with a limited duration, after which a landslide database is no longer kept up-to-date. Therefore, it is very difficult to obtain landslide inventory maps that are complete, both with respect to the area covered and to the time period investigated [33].

Determining temporal probability is done either by correlating the data on landslide occurrences with those of the triggering factors (provided that the historical records are sufficient for this) or through dynamic modelling [33]. Jaiswal and Van Westen [11] proposed a method that based on the Poisson model to determine the temporal probability of landslide initiation along transportation routes. The model is applicable to shallow debris slides and debris flows associated with cut slopes and triggered by rainfall. This method is suitable with his study area because of the plenty of the historical landslide records and rainfall records and having a rain gauge station network good enough for applying Poisson model.

With the limitations of database and a lack of rain gauge station network that can be distributed regularly in the study area, so we cannot produce a map on spatial landslide probability distribution as in the research results of Berti [21]. Although we confront with many difficulties about the database but the results of this paper need to encourage and apply widely in the high risk areas of landslide hazard, especially in the mountainous area of Vietnam.

Finally, we still believe that the results of this paper can helps local authorities and local people to be aware of the negative impacts of landslides triggered by rainfall events as well as help them in the selection the most suitable development planning methods for the study area to avoid badly effects, risk mitigation and damages in the future.

\section{Conclusions}

In the study area, landslide triggering is significantly controlled by an empirical minimum rainfall threshold: $R_{T}=40.8-0.201 \mathrm{R}_{3 \mathrm{ad}}$. The Bayesian probability model for one-dimensional case was established based on 26 landslides for the period 1989 to 2009; daily rainfall data with the same time and the values of probability varies from 0.03 to 0.44 . Next, the Bayesian probability model for two-dimensional case was generated based on 10 landslides; rainfall intensity and duration in three months (May, June and July) of 2013 and the values of probability ranges from 0.08 to 0.67 , and computed values of conditional 
landslide probability $P(A \mid B)$ from two-dimensional case of Bayesian approach are clearly controlled by rainfall intensity $>40 \mathrm{~mm}$ with rainfall duration $>0.3$ day.

We have proposed an approach by combining an empirical minimum rainfall threshold model with a probability model for determining probability of landslide occurrence over an area by using Bayesian probability method. In this model, the value of minimum rainfall threshold of the study area is an important referential parameter related to rainfall intensity and rainfall duration for the application of Bayesian probability method in calculating the probability of landslide occurrence.

The model may not be applicable if the exact dates of landslide events in the past are not known. The results of the model will be better if the input data on daily rainfall, hourly rainfall from a well-distributed network of rain gauges is combined with the actual dates of landslide occurrences.

The computed landslide probability is dependent strongly on a well-distributed network of rain gauges in a well-defined area.

From the results of this research, we also want to continue our studies in other mountainous area of Vietnam as future works. To fulfill this objective, the installation of a well-distributed network of rain gauges in mountainous area of Vietnam is a strong recommendation of us in order to test the practical effectiveness of the proposed method in a wide variety of geological conditions.

\section{Acknowledgements}

We acknowledge the help of the Vietnam Institute of Geosciences and Mineral Resources (VIGMR) for providing relevant data and support. This paper was carried out as a part of the first author's PhD studies at the Faculty of Engineering, China University of Geosciences (Wuhan), China. The authors also thank the three anonymous reviewers of Open Journal of Geology for relevant comments and Joanna Cheng, the Managing Editor, for assistance.

\section{References}

[1] Caine, N. (1980) The Rainfall Intensity-Duration Control of Shallow Landslides and Debris Flows. Geografiska Annaler A, 62, 23-27.

[2] Crosta, G. (1998) Rationalization of Rainfall Threshold: An Aid to Landslide Hazard Evaluation. Environmental Geology, 35, 131-145.

https://doi.org/10.1007/s002540050300

[3] Crozier, M.J. (1999) Prediction of Rainfall-Triggered Landslides: A Test of the Antecedent Water Status Model. Earth Surface Processes and Landforms, 24, 825-833. https://doi.org/10.1002/(SICI)1096-9837(199908)24:9<825::AID-ESP14>3.0.CO;2$\underline{\mathrm{M}}$

[4] Aleotti, P. (2004) A Warning System for Rainfall-Induced Shallow Failures. Engineering Geology, 73, 247-265. https://doi.org/10.1016/j.enggeo.2004.01.007

[5] Wieczorek, F. and Glade, T. (2005) Climatic Factors Influencing Occurrence of Debris Flows. Debris-Flow Hazards and Related Phenomena. Springer, Berlin, Sec. 14, 325-362. https://doi.org/10.1007/3-540-27129-5_14 
[6] Guzzetti, F., Peruccacci, S., Rossi, M. and Stark, C.P. (2007) Rainfall Thresholds for the Initiation of Landslides in Central and Southern Europe. Meteorology and Atmospheric Physics, 98, 239-267. https://doi.org/10.1007/s00703-007-0262-7

[7] Guzzetti, F., Peruccacci, S., Rossi, M. and Stark, C.P. (2008) The Rainfall Intensity-Duration Control of Shallow Landslides and Debris Flows: An Update. Landslides, 5, 3-17. https://doi.org/10.1007/s10346-007-0112-1

[8] Saito, H., Nakayama, D. and Matsuyama, H. (2010) Relationship between the Initiation of a Shallow Landslide and Rainfall Intensity-Duration Thresholds in Japan. Geomorphology, 118, 167-175. https://doi.org/10.1016/j.geomorph.2009.12.016

[9] Glade, T., Crozier, M. and Smith, P. (2000) Applying Probability Determination to Refine Landslide-Triggering Rainfall Thresholds Using an Empirical "Antecedent Daily Rainfall Model”. Pure and Applied Geophysics, 157, 1059-1079. https://doi.org/10.1007/s000240050017

[10] Zêzere, J.L., Trigo, R. and Trigo, I. (2005) Shallow and Deep Landslides Induced by Rainfall in the Lisbon Region (Portugal): Assessment of Relationships with the North Atlantic Oscillation. Natural Hazards and Earth System Sciences, 5, 331-344. https://doi.org/10.5194/nhess-5-331-2005

[11] Jaiswal, P. and Van Westen, C.J. (2009) Estimating Temporal Probability for Landslide Initiation along Transportation Routes Based on Rainfall Thresholds. Geomorphology, 112, 96-105. https://doi.org/10.1016/j.geomorph.2009.05.008

[12] Lee, D.-H., Lai, M.-H., Wu, J.-H., Chi, Y.-Y., Ko, W.-T. and Lee, B.-L. (2013) Slope Management Criteria for Alishan Highway Based on Database of Heavy Rainfall-Induced Slope Failures. Engineering Geology, 162, 97-107.

https://doi.org/10.1016/j.enggeo.2013.04.012

[13] Zêzere, J.L., Pereira, T.V.S., Oliveira, S.C., Marques, R. and Garcia, R.A.C. (2015) Rainfall Thresholds for Landslide Activity in Portugal: A State of the Art. Environmental Earth Sciences, 73, 2917-2936. https://doi.org/10.1007/s12665-014-3672-0

[14] Lainas, S., Sabatakakis, N. and Koukis, G. (2016) Rainfall Thresholds for Possible Landslide Initiation in Wildfire-Affected Areas of Western Greece. Bulletin of Engineering Geology and the Environment, 75, 883-896. https://doi.org/10.1007/s10064-015-0762-5

[15] Afungang, R.N. and Bateira, C.V. (2016) Temporal Probability Analysis of Landslides Triggered by Intense Rainfall in the Bamenda Mountain Region, Cameroon. Environmental Earth Sciences, 75, 1032. https://doi.org/10.1007/s12665-016-5835-7

[16] Palenzuela, J.A., Jiménez-Perálvarez, J.D., Chacón, J. and Irigaray, C. (2016) Assessing Critical Rainfall Thresholds for Landslide Triggering by Generating Additional Information from a Reduced Database: An Approach with Examples from the Betic Cordillera (Spain). Natural Hazards, 84, 185-212. https://doi.org/10.1007/s11069-016-2416-8

[17] Naidu, S., Sajinkumar, K.S., Oommen, T., Anuja, V.J. and Samuel, R.A. (2017) Early Warning System for Shallow Landslides Using Rainfall Threshold and Slope Stability Analysis. China University of Geosciences, Geoscience Frontiers, Beijing, 1-12. https://doi.org/10.1016/j.gsf.2017.10.008

[18] Peruccacci, S., Brunetti, M.T., Gariano, S.L., Melillo, M., Rossi, M. and Guzzetti, F. (2017) Rainfall Thresholds for Possible Landslide Occurrence in Italy. Geomorphology, 290, 39-57. https://doi.org/10.1016/j.geomorph.2017.03.031

[19] Palladino, M.R., Viero, A., Turconi, L., Brunetti, M.T., Peruccacci, S., Melillo, M., Luino, F., Deganutti, A.M. and Guzzetti, F. (2018) Rainfall Thresholds for the Acti- 
vation of Shallow Landslides in the Italian Alps: The Role of Environmental Conditioning Factors. Geomorphology, 303, 53-67.

https://doi.org/10.1016/j.geomorph.2017.11.009

[20] Floris, M. and Bozzano, F. (2008) Evaluation of Landslide Reactivation: A Modified Rainfall Threshold Model Based on Historical Records of Rainfall and Landslides. Geomorphology, 94, 40-57. https://doi.org/10.1016/j.geomorph.2007.04.009

[21] Berti, M., Martina, M.L.V., Franceschini, S., Pignone, S., Simoni, A. and Pizziolo, M. (2012) Probabilistic Rainfall Thresholds for Landslide Occurrence Using a Bayesian Approach. Journal of Geophysical Research, 117, F04006. https://doi.org/10.1029/2012JF002367

[22] Bui, D.T., Pradhan, B., Lofman, O., Revhaug, I. and Dick, O.B. (2013) Regional Prediction of Landslide Hazard Using Probability Analysis of Intense Rainfall in the Hoa Binh Province, Vietnam. Natural Hazards, 66, 707-730. https://doi.org/10.1007/s11069-012-0510-0

[23] Long, N.T. (2008) Landslide Susceptibility Mapping of the Mountainous Area in a Luoi District, Thua Thien Hue Province, Vietnam. PhD Dissertation, Vrije University of Brussel, Brussel, 255 p.

[24] Hue, T.T., Duong, T.V., Toan, D.V., Nghinh, L.T., Minh, V.C., Pho, N.V., Xuan, P.T., Hoan, L.T., Huyen, N.X., Pha, P.D., Chinh, V.V. and Thom, B.V. (2004) Investigation and Assessment of the Types of Geological Hazard in the Territory of Vietnam and Recommendation of Remedial Measures. Phase II: A Study of the Northern Mountainous Province of Vietnam. Institute of Geological Sciences, Vietnam Academy of Science and Technology, Hanoi, 361 p. (In Vietnamese)

[25] Thinh, D.V., Dong, N.P., Hong, P.M., Hung, P.V., Khoi, T.N., Ke, T.D., Phu, D.V., Thang, P.X., Thanh, P.V., Thang, P.H., Thay, B.V., Thinh, N.T., Thien, T.V., Tu, M.T. and Vinh, B.X. (2005) The Investigated Report of Natural Hazards in the Northwest of Vietnam. Northern Geological Mapping Division, Hanoi. (In Vietnamese)

[26] Khien, N.X., Hung, L.Q., Long, N.T. and Hien, D.M. (2012) Assessment of Status Geohazards in Four Mountainous Provinces in North of Viet Nam. In: Giang, H., Kan, B., Bang, C. and Quang, T., Eds., Identification of Sources, Prediction and Propose Preventive Measures and Consequences Mitigation, Vietnam Institute of Geosciences and Mineral Resources, Hà Nội, 322. (In Vietnamese)

[27] Hung, L.Q., Van, N.T.H., Son, P.V., Ninh, N.H., Tam, N. and Huyen, N.T. (2017) Landslide Inventory Mapping in the Fourteen Northern Provinces of Vietnam: Achievements and Difficulties. 4th World Landslide Forum, Ljubljana, 29 May-2 June 2017, 501-510.

[28] Polemio, M. and Sdao, F. (1999) The Role of Rainfall in the Landslide Hazard: The Case of the Avigliano Urban Area (Southern Apennines, Italy). Engineering Geology, 53, 297-309. https://doi.org/10.1016/S0013-7952(98)00083-0

[29] Dahal, R.K. and Hasegawa, S. (2008) Representative Rainfall Thresholds for Landslides in the Nepal Himalaya. Geomorphology, 100, 429-443. https://doi.org/10.1016/j.geomorph.2008.01.014

[30] Martelloni, G., Segoni, S., Fanti, R. and Catani, F. (2011) Rainfall Thresholds for the Forecasting of Landslide Occurrence at Regional Scale. Landslides, 9, 485-495. https://doi.org/10.1007/s10346-011-0308-2

[31] Driver, J.F. and Alemi, F. (1995) Forecasting without Historical Data: Bayesian Probability Models Utilizing Expert Opinions. Journal of Medical Systems, 19, 359-374. https://doi.org/10.1007/BF02257266 
[32] Brunetti, M.T., Peruccacci, S., Rossi, M., Luciani, S., Valigi, D. and Guzzetti, F. (2010) Rainfall Thresholds for the Possible Occurrence of Landslides in Italy. Natural Hazards and Earth System Sciences, 10, 447-458.

https://doi.org/10.5194/nhess-10-447-2010

[33] Van Westen, C.J., Van Asch, T.W.J. and Soeters, R. (2006) Landslide Hazard and Risk Zonation-Why Is It Still so Difficult? Bulletin of Engineering Geology and the Environment, 65, 167-184. https://doi.org/10.1007/s10064-005-0023-0 